\title{
Robot-assisted excision of thyroglossal duct cyst by a postauricular facelift approach
}

\author{
Dong Won Lee ${ }^{1}$, Kyung Tae ${ }^{2}$ \\ ${ }^{1}$ Department of Otolaryngology-Head and Neck Surgery, School of Medicine, Catholic University of Daegu, Daegu, Korea (South) \\ ${ }^{2}$ Department of Otolaryngology-Head and Neck Surgery, College of Medicine, Hanyang University, Seoul, Korea (South)
}

Videosurgery Miniinv 2020; 15 (1): 245-248

DOI: https://doi.org/10.5114/wiitm.2019.88751

\begin{abstract}
Introduction: A trend towards robotic scarless surgery using remote site incisions has developed in head and neck surgery for better cosmetic outcomes. We have carried out robot-assisted excision of thyroglossal duct cysts (TGDC) by a postauricular facelift approach to avoid visible scars in the central neck related to the trans-cervical Sistrunk operation.

Aim: To evaluate the technical feasibility and safety of robot-assisted excision of TGDC by a postauricular facelift approach.

Material and methods: Six patients who underwent robot-assisted excision of TGDC by a postauricular facelift approach were analyzed.

Results: The robotic procedures were done successfully in all patients, without any conversion to a trans-cervical approach or incomplete removal of the lesions. In terms of cosmetic satisfaction, three patients were "very satisfied" and three were "satisfied".

Conclusions: Robot-assisted Sistrunk operations for TGDC by a postauricular facelift approach are feasible and safe and yield excellent postoperative cosmesis.
\end{abstract}

Key words: thyroglossal duct cyst, robotic surgery, Sistrunk operation, postauricular facelift approach.

\section{Introduction}

A trend towards scarless and minimally invasive surgery using an endoscope and surgical robotic system has developed in head and neck surgery over the last two decades in order to achieve better cosmetic results and to reduce surgical morbidity. Various remote access approaches using axillary, breast, anterior chest, transoral, and postauricular incisions have been developed to hide neck scars associated with surgery involving thyroid, parathyroid, submandibular gland, and other neck masses [1-3].

We have performed robotic and endoscopic surgery for the thyroid, parathyroid or submandibular glands, as well as branchial cleft cysts and other neck masses, since 2005, using transaxillary, postauricular facelift and transoral approaches [4-8].

We have also carried out robot-assisted excision of thyroglossal duct cysts by a postauricular facelift approach in order to avoid visible scars in the central neck related to the trans-cervical Sistrunk operation.

\section{Aim}

Herein, we describe the surgical procedure used and the early surgical outcomes of this novel technique based on our experience of six cases.

\section{Address for correspondence}

Prof. Kyung Tae, Department of Otolaryngology-Head and Neck Surgery, College of Medicine, Hanyang University, 222 Wangsimni-ro, 04763 Seoul, Korea (South), e-mail: kytae@hanyang.ac.kr 


\section{Material and methods}

\section{Patients}

This study included 6 consecutive patients with thyroglossal duct cysts (TGDCs) who underwent robot-assisted excision by a postauricular facelift approach between September 2015 and June 2017. All robotic procedures were performed by a single surgeon (K.T.) using the da Vinci Si surgical system (Intuitive Surgical, Sunnyvale, CA, USA). Contraindications included signs of infection or cutaneous fistula, and previous surgery or radiotherapy to the neck. All patients provided informed consent for robotic excision of TGDC. The study was approved by the institutional review board of Hanyang University Hospital (HYUH 2019-03-010-001).

Surgical outcomes including operative time, conversion to a transcervical approach, amount of drainage, and complications, were evaluated. Subjective postoperative cosmetic results were evaluated after 3 months using a questionnaire about satisfaction with incision site scarring and neck contour.

\section{Surgical technique}

The patient was placed in a supine position with the head rotated to the opposite side of the incision, under general anesthesia with endotracheal intubation. The side of the skin incision was decided according to the location of the lesion. A right postauricular skin incision was used if the lesion was located in the true midline or deviated slightly to the right. A left skin incision was used if the lesion deviated to the left. The postauricular facelift incision start-

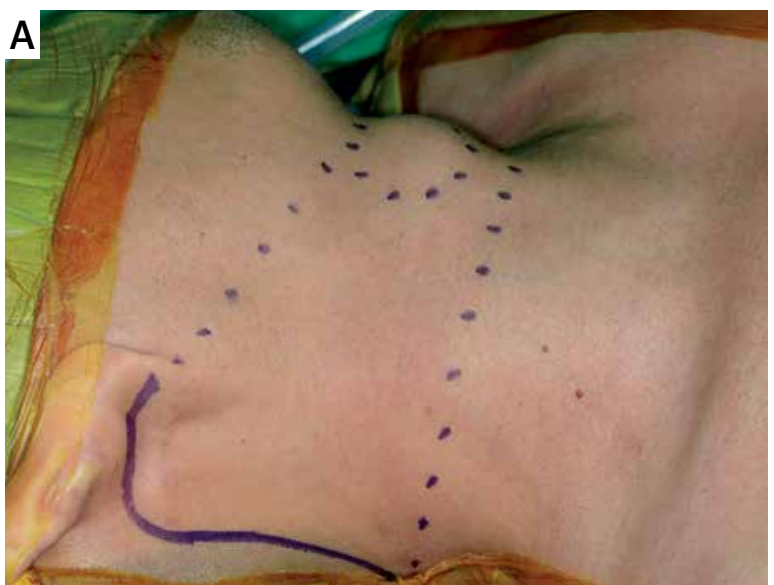

ed from the lower end of the postauricular sulcus, progressed to the upper part, curved posteriorly in the upper third of the auricle and proceeded downwards to follow the occipital hairline (Photo $1 \mathrm{~A}$ ). A skin flap was elevated at the subplatysma muscle level above the sternocleidomastoid (SCM) muscle by monopolar cautery under direct vision, inferiorly to the level of the isthmus of the thyroid, superiorly to the lower border of the mandible, and medially to expose the whole cystic lesion (Photo $1 \mathrm{~B}$ ). The greater auricular nerves and external jugular veins were identified and preserved.

After an external retractor (L\&C Bio, Seoul, Korea) had been placed under the skin flap to maintain a working space without $\mathrm{CO}_{2}$ gas insufflation, four robotic arms, including a 30-degree endoscope, Maryland dissectors, Prograsp forceps, and Harmonic curved shears or monopolar curved scissors, were inserted through the postauricular facelift incision.

The dissection was carried out by dividing and cutting the strap muscles with the monopolar curved scissors and Harmonic curved shears to expose the cystic mass below the hyoid bone (Photo 2 A). The lower part of the cyst was usually dissected first, and the cyst was peeled from the surrounding connective tissue while taking care not to rupture it.

The suprahyoid muscles attached to the hyoid bone were cut to skeletonize the body of the bone (Photo 2 B). To cut the hyoid bone, the 4 robotic arms were pulled out of the working space. The body of the bone was cut between the lesser horns using a conventional bone cutter under direct vision, because a robotic bone cutter is not available in the da

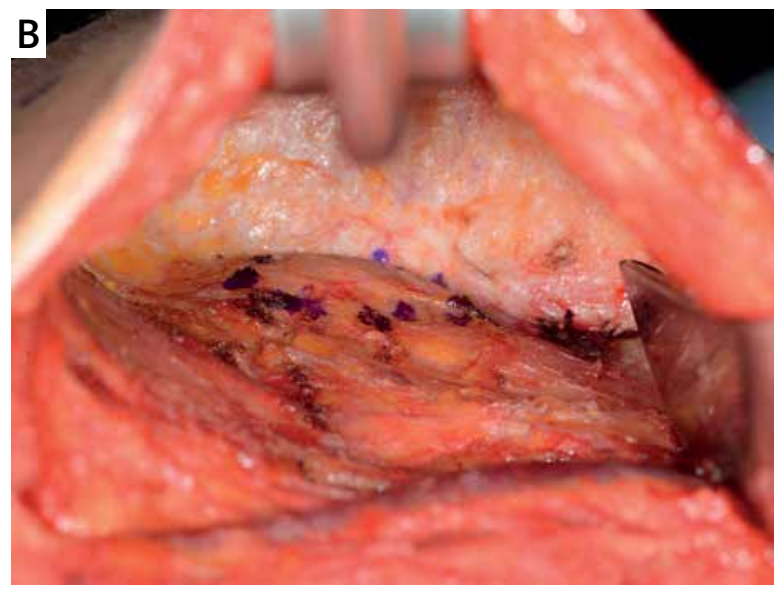

Photo 1. A - A postauricular facelift skin incision is made at the postauricular sulcus, extending along the occipital hairline. B - The skin flap is elevated and lifted using an external retractor to create a working space 

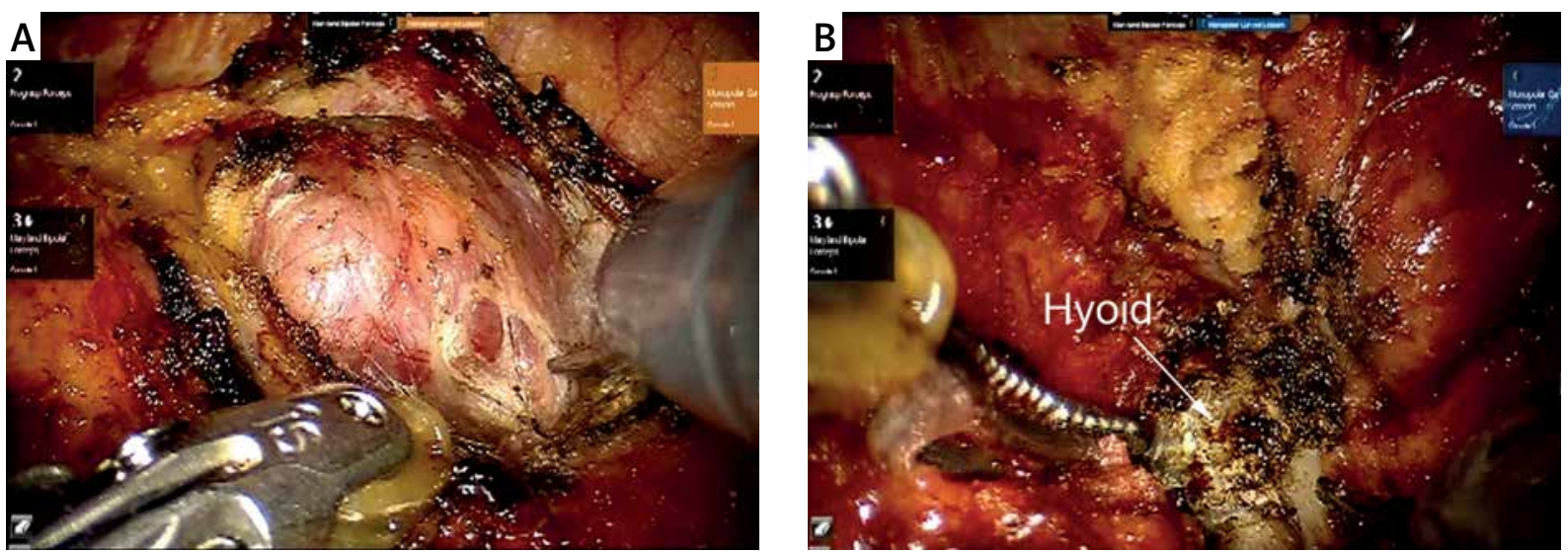

Photo 2. The robot-assisted Sistrunk operation. A - A cystic mass is noted inferior to the hyoid bone, and a dissection is carried out by dividing and cutting the strap muscles to expose the cystic lesion. B - The body of the hyoid bone is identified and skeletonized before resecting it with a bone cutter

Vinci Si surgical system. Great care was taken not to injure the lingual artery and hypoglossal nerve when cutting the hyoid bone. If any tract was connected to the base of the tongue, it was traced and removed completely. After removing the TGDC, a negative suction drainage tube was placed, and the skin incision was closed layer by layer.

\section{Results}

The clinical characteristics of the patients and surgical outcomes are shown in Table I. Of the 6 patients, 5 were male. Mean age was $31.2 \pm 13.2$ years. All the cysts were of the infrahyoid type, and their mean size was $29.5 \pm 5.8 \mathrm{~mm}$. Robot-assisted excision of the TGDCs by a postauricular facelift approach was performed successfully without any conversion to a transcervical approach. The skin incision was on the right side in 5 cases, and the mean operative time including skin flap elevation and excision of the TGDC was $187.5 \pm 34.0$ min (range: 135-225). The mean postoperative drainage was $216.7 \pm 99.0 \mathrm{ml}$ (range: $115-340$ ), and the mean duration of drainage was $4.3 \pm 0.5$ days (range: $4-5$ ). The mean hospital stay was $5.8 \pm 0.8$ days (range: 5-7). One patient suffered transient marginal nerve palsy, which recovered within 2 months. Seroma occurred in 1 patient, and was resolved by repeat aspiration. The mean follow-up period was about 1.5 years but there has been no recurrence up to the time of writing. Three patients were "very satisfied" and three "satisfied" with their cosmetic outcomes at 3 months postoperatively.

Table I. Characteristics and surgical outcomes of patients with thyroglossal duct cyst

\begin{tabular}{|c|c|c|c|c|c|c|c|c|c|c|}
\hline Patient & Gender & Age & $\begin{array}{l}\text { Size } \\
\text { of cyst } \\
{[\mathrm{cm}]}\end{array}$ & $\begin{array}{c}\text { Type } \\
\text { of TGDC }\end{array}$ & $\begin{array}{l}\text { Approach } \\
\text { side }\end{array}$ & $\begin{array}{c}\text { Operative } \\
\text { time } \\
\text { [min] }\end{array}$ & $\begin{array}{c}\text { Amount } \\
\text { of drainage } \\
{[\mathrm{ml}]}\end{array}$ & $\begin{array}{l}\text { Hospital } \\
\text { stay } \\
\text { [days] }\end{array}$ & $\begin{array}{l}\text { Complica- } \\
\text { tions }\end{array}$ & $\begin{array}{l}\text { Cosmetic } \\
\text { outcomes }\end{array}$ \\
\hline 1 & $M$ & 44 & $4 \times 3$ & Infrahyoid & Right & 135 & 220 & 5 & None & Satisfied \\
\hline 2 & $M$ & 27 & $3.5 \times 3.4$ & Infrahyoid & Right & 225 & 125 & 6 & $\begin{array}{c}\text { transient } \\
\text { marginal } \\
\text { nerve palsy }\end{array}$ & Satisfied \\
\hline 3 & $\mathrm{~F}$ & 45 & $3.4 \times 2.7$ & Infrahyoid & Right & 185 & 330 & 6 & None & Satisfied \\
\hline 4 & $M$ & 38 & $3.5 \times 3$ & Infrahyoid & Right & 220 & 340 & 6 & Seroma & $\begin{array}{c}\text { Very } \\
\text { satisfied }\end{array}$ \\
\hline 5 & $M$ & 13 & $3 \times 2$ & Infrahyoid & Left & 165 & 115 & 7 & None & $\begin{array}{c}\text { Very } \\
\text { satisfied }\end{array}$ \\
\hline 6 & $M$ & 20 & $2 \times 2$ & Infrahyoid & Right & 195 & 170 & 5 & None & $\begin{array}{c}\text { Very } \\
\text { satisfied }\end{array}$ \\
\hline
\end{tabular}




\section{Discussion}

The TGDC is the most common congenital neck mass, and usually presents as a midline neck mass. Sometimes inflammation causes symptoms such as severe swelling and pain. In most cases there is no severe discomfort, but treatment is necessary to prevent recurrent infection of the cyst and eliminate the potential for malignant transformation [9]. The cosmetic problems caused by the mass are further reasons for surgical treatment [10]. The primary treatment of TGDC is surgical removal, known traditionally as the Sistrunk operation, described in the 1920s. Removal of the central portion of the hyoid is necessary to minimize the risk of recurrence because any TGDC remnants are usually associated with the hyoid body. Although the operation is safe and effective, it leaves an anterior neck incision scar, which is one of the main reasons for some patients' dissatisfaction after surgery. We therefore perform the robot-assisted Sistrunk operation using a postauricular facelift approach to improve postoperative cosmesis.

Robot-assisted excision of TGDCs by a postauricular facelift approach was successful, without any conversion to a trans-cervical approach or incomplete removal of the lesions. This result suggests that robot-assisted excision of TGDCs is feasible and effective.

The da Vinci robotic surgical system provides a 10- to 12-fold magnified 3-dimensional view with full access to deep structures. It also reduces hand tremor, and permits precise dissection and multi-articulated motion. Counter traction can be performed during the operation, using the $3^{\text {rd }}$ robotic instrument, Prograsp forceps. This facilitates dissection of the lesion and increases surgical versatility.

However, during the robot-assisted operation it is very difficult to remove the body of the hyoid bone with the robotic instruments, because no robotic bone cutter is available. Hence a robotic bone cutter needs to be developed. If there is tract connected to the base of the tongue, a combined transoral robotic approach (TORS) can be used to remove it completely. However, in our cases, there was no tract to be removed.

There was one instance of transient marginal nerve palsy. This may have been related to the need to retract the skin flap tightly to maintain the working space during the robotic procedure.
Fortunately, there was no recurrence of TGDC. However, a further study with a larger number of cases and long-term follow-up is required to evaluate accurately the efficacy of robot-assisted TGDC excision.

\section{Conclusions}

Robot-assisted Sistrunk operations for TGDC by a postauricular facelift approach are feasible and safe, and yield excellent postoperative cosmesis. Our preliminary experience suggests that it could be useful for patients with TGDC who wish to hide anterior neck scarring.

\section{Conflict of interest}

The authors declare no conflict of interest.

\section{References}

1. Tae K, Ji YB, Song CM, et al. Robotic and endoscopic thyroid surgery: evolution and advances. Clin Exp Otorhinolaryngol 2019; 12: 1-11.

2. Kim CH, Byeon HK, Shin YS, et al. Robot-assisted Sistrunk operation via a retroauricular approach for thyroglossal duct cyst. Head Neck 2014; 36: 456-8.

3. Byeon HK, Ban MJ, Lee JM, et al. Robot-assisted Sistrunk's operation, total thyroidectomy, and neck dissection via a transaxillary and retroauricular (TARA) approach in papillary carcinoma arising in thyroglossal duct cyst and thyroid gland. Ann Surg Oncol 2012; 19: 4259-61.

4. Singh RP, Sung ES, Song CM, et al. Robot-assisted excision of the submandibular gland by a postauricular facelift approach: comparison with the conventional transcervical approach. $\mathrm{Br}$ J Oral Maxillofac Surg 2017; 55: 1030-4.

5. Tae K, Ji YB, Song CM, et al. Robotic selective neck dissection by a postauricular facelift approach: comparison with conventional neck dissection. Otolaryngol-Head Neck Surg 2014; 150: 394-400.

6. Song CM, Ji YB, Kim KR, et al. Robot-assisted excision of branchial cleft cysts using a postauricular facelift approach. Auris Nasus Larynx 2015; 42: 424-7.

7. Sung ES, Ji YB, Song CM, et al. Robotic thyroidectomy: comparison of a postauricular facelift approach with a gasless unilateral axillary approach. Otolaryngol-Head Neck Surg 2016; 154: 997-1004.

8. Tae K, Lee DW, Song CM, et al. Early experience of transoral thyroidectomy: comparison of robotic and endoscopic procedures. Head Neck 2019; 41: 730-8.

9. Foley DS, Fallat ME. Thyroglossal duct and other congenital midline cervical anomalies. Semin Pediatr Surg 2006; 15: 70-5.

10. Rohof D, Honings J, Theunisse HJ, et al. Recurrences after thyroglossal duct cyst surgery: results in 207 consecutive cases and review of the literature. Head Neck 2015; 37: 1699-704.

Received: 11.07.2019, accepted: 9.08.2019. 